\title{
Design of Rocker Bogie Mechanism
}

\author{
D. S. Chinchkar ${ }^{1}$, S. S. Gajghate ${ }^{2}$, R. N. Panchal ${ }^{3}$, R. M. Shetenawar ${ }^{4}$, P. S. Mulik ${ }^{5}$ \\ Assistant Professor, Mechanical Engineering, AGTI's Dr. Daulatrao Aher College of Engineering, Karad, India ${ }^{1,2,4}$ \\ Associate Professor, Mechanical Engineering, AGTI's Dr. Daulatrao Aher College of Engineering, Karad, India ${ }^{3}$ \\ Graduate Student, Mechanical Engineering, AGTI's Dr. Daulatrao Aher College of Engineering, Karad, India ${ }^{5}$
}

\begin{abstract}
Rocker bogie are important for conducting in-situ scientific analysis of objectives that are separated by many meters to tens of kilometers. Current mobility designs are complex, using many wheels or legs. They are open to mechanical failure caused by the harsh environment on Mars. A four wheeled rover capable of traversing rough terrain using an efficient high degree of mobility suspension system. The primary mechanical feature of the rocker bogiedesign is its drive train simplicity, which is accomplished by using only two motors for mobility. Both motors are located inside the body where thermal variation is kept to a minimum, increasing reliability and efficiency. Four wheels are used because there are few obstacles on natural terrain that require both front wheels of the rover to climb simultaneously. A series of mobility experiments in the agriculture land, rough roads, inclined, stairs and obstacles surfaces concluded that rocker bogiecan achieve some distance traverses on field.
\end{abstract}

Keywords: Rocker bogie; Wheel type mobile robot; Stair climbing; Rover.

\section{INTRODUCTION}

Over the past decade, the rocker-bogie suspension design has become a proven mobility application known for its superior vehicle stability and obstacle-climbing capability. Following several technology and research rover implementations, the system was successfully flown as part of Mars Pathfinder's Sojourner rover. When the Mars Exploration Rover (MER) Project was first proposed, the use of a rocker-bogie suspension was the obvious choice due to its extensive heritage. The challenge posed by MER was to design a lightweight rocker-bogie suspension that would permit the mobility to stow within the limited space available and deploy into a configuration that the rover could then safely use to egress from the lander and explore the Martian surface [4].

When building a robot you'd like it to be as simple as possible. In most cases you'd never need a suspension system, but there were several instances when a suspension system cannot be avoided. The term "bogie" refers to the links that have a drive wheel at each end. Bogies were commonly used as load wheels in the tracks of army tanks as idlers distributing the load over the terrain. Bogies were also quite commonly used on the trailers of semi-trailer trucks. Both applications now prefer trailing arm suspensions.The rocker-bogie design has no springs or stub axles for each wheel, allowing the rover to climb over obstacles, such as rocks, that are up to twice the wheel's diameter in size while keeping all six wheels on the ground. As with any suspension system, the tilt stability is limited by the height of the centre of gravity.

\section{LITERATURE REVIEW}

The concept of our research work is to create a rockerbogie drive system based on those of NASA. NASA developed the rocker-bogie suspension system for their rovers and was implemented in the Mars Pathfinder's and Sojourner rover. The rocker-bogie suspension system passively keeps all six wheels on the robot in contact with the ground even on uneven surfaces. This creates for great traction and manoeuvrability (Harrington \& Voorhees).

The rocker-bogie suspension mechanism which was currently NASA's approved design for wheeled mobile robots, mainly because it had study or resilient capabilities to deal with obstacles and because it uniformly distributes the payload over its 6 wheels at all times. It also can be used for other purposes to operate in rough roads and to climb the steps. It was having lots of advantages but one of the major disadvantages is the rotation of the mechanism when and where is required. The rotation can be possible by providing individual motors to individual wheels which causes arise in cost and complicacy in design. Here an attempt was made to modify the existing design by incorporating a gear type steering mechanism which will be operated by a single motor which simplifies the design as well as the total cost and operating cost of the mechanism.

In this work the proposed steering mechanism was designed and the modeling was done in CATIA (V-5) and the same was analyzed for static analysis for the proposed torque condition of the motor in ANSYS. All the results in the analysis were analyzed for static analysis [1].

The researchers discusses the concept and parameter design of a Robust Stair Climbing Compliant Modular Robot, capable of tackling stairs with overhangs. Modifying the geometry of the periphery of the wheels of our robot helps in tackling overhangs. Along with establishing a concept design, robust design parameters were set to minimize performance variation. The Grey- 


\section{IARJSET}

based Taguchi Method was adopted for providing an Important fields of application are homelandsecurity, optimal setting for the design parameters of the robot. The surveillance, demining, reconnaissance in dangerous robot prototype was shown to have successfully scaled situations, and agriculture. The design of thelocomotion stairs of varying dimensions, with overhang, thus systems of mobile robots for unstructured environments corroborating the analysis performed [2].

An analysis method to make the rocker bogie mechanism can climb up a stair was achieved in the work. The east coast of Malaysia faced a massive flood from heavy downpour, leading to huge flood damage and caused irreparable loss to life and property. The flood carries the debris, soil and trees along their path, damaging the road and building structure, leaving the road become uneven. This situation gives difficulty to task force bearing aids during the post disaster management. The research paper proposed an intelligent inclined motion control of an amphibious vehicle while moving on uneven terrain surface [3]. was generally complex, particularly whenthey were required to move on uneven or soft terrains, or to climb obstacles. The three main categories of locomotion systems (wheeled $-\mathrm{W}$, tracked $-\mathrm{T}$ and legged $-\mathrm{L}$ ) and the four hybrid categories that can be derived by combining these main locomotion systems were discussed with referenceto maximum speed, obstacle-crossing capability, step/stair climbing capability, slope climbing capability,walking capability on soft terrains, walking capability on uneven terrains, energy efficiency, mechanical complexity,control complexity and technology readiness. The current and future trends of mobile robotics were discussed [7].

The research paper deals with the designing and modeling of stair climbing robot based on the well-known rocker bogie mechanism in Ansys rigid body dynamics module. The robots often suffer from undesired phenomenon slip, sticking and floating while climbing steps and stairs, which may cause instability of the mobile robot. The Taguchi method was used to chosen as an optimization tool to make trajectory of center of mass close to straight line while all wheels keep in contact with ground during climbing stairs. Taguchi method was adopted due to its simplicity and cost effectiveness both in formulating the objective function and satisfying multiple constraints simultaneously. In the Optimization, Seven kinematic parameters of rocker bogie mechanism were optimized which include four link lengths $\left(1_{1}, 1_{2}, l_{3}\right)$ and three wheel radius $\left(R_{1}, R_{2}, R_{3}\right)$. The kinematic Model of proposed mechanism was built and it was simulated in ANSYS Rigid body dynamics. Three different shapes of typical stairs were selected as user conditions to determine a robust optimal solution. The result obtained shows the variation of center of mass position with time, variation of velocity of joint with time, variation of force with time [5]. It was basically a suspension arrangement used in mechanical robotic vehicles used specifically for space exploration. The rocker-bogie suspension based rovers has been successfully introduced for the Mars Pathfinder and Mars Exploration Rover (MER) and Mars Science Laboratory (MSL) missions conducted by apex space exploration agencies throughout the world. The proposed suspension system was currently the most favored design for every space exploration company indulge in the business of space research. The motive the research initiation was to understand mechanical design and its advantages of Rocker- bogie suspension system in order to find suitability to implement it in conventional loading vehicles to enhance their efficiency and also to cut down the maintenance related expenses of conventional suspension systems [6].

The world market of mobile robotics was expected to increase substantially in the next 20 year, surpassing the market of industrial robotics in terms of units and sales.

The optimization of a particular suspension system known as the "rocker-bogie" for our Mars Rover. This type of mechanism has beenused on most of the rovers on Mars and has proved to be a simple and elegant design. A GeneticAlgorithm was implemented and used to optimize the geometry and kinematics of the rover'swheel suspension system subject to the defined performance metrics. This work shows the effectiveness of the optimization of a rocker-bogie suspension systemusing a Genetic Algorithm. It also reveals that the resulting system meets all constraints andthat significantly reduces the error of individual performance metrics and the overall system.It was shown that the overall fitness of the rover suspension system can be increased by anaverage of $28 \%$ after 100 iterations compared to an initial guess. All performance metricsdefined were improved significantly throughout the optimization. The method can be applied to different types of rovers in order to optimize the wheelsuspension mechanism's geometry [8].

\section{DESIGN OF ROCKER BOGIE}

The important factor in manufacturing of rocker bogie mechanism is to determine the dimensions of rocker and bogie linkages and angles between them. The lengths and angles of this mechanism can be changed as per requirement. In the work aim is to manufacture the rocker bogie mechanism which can overcome the obstacles of $150 \mathrm{~mm}$ height (like stones, wooden blocks) and can climb over stairs of height $150 \mathrm{~mm}$. Also another target is to climb any surface at an angle of $45^{\circ}$. To achieve the above targets we had design the rocker-bogie model by assuming stair height $150 \mathrm{~mm}$ and length $370 \mathrm{~mm}$.

Using Pythagoras theorem, find the dimensions of the model. It have both angles of linkages are $90^{\circ}$.

\section{A. Design calculation}

The objective of the research work is stair climbing. To achieve proper stair climbing the dimensions of linkages should be proper. Assume the stair height and length 150 $\mathrm{mm}$ and $370 \mathrm{~mm}$ respectively. To climb stairs with higher 
IARJSET

stability, it is required that only one pair of wheel should be in rising position at a time. Hence to find dimension of bogie linkages, first pair of wheels should be placed at horizontal position means at the end of the rising as shown in Fig.1. And second pair should be placed just before the start of rising. There should be some distance between vertical edge of stair and second pair of wheel to striking of wheels.

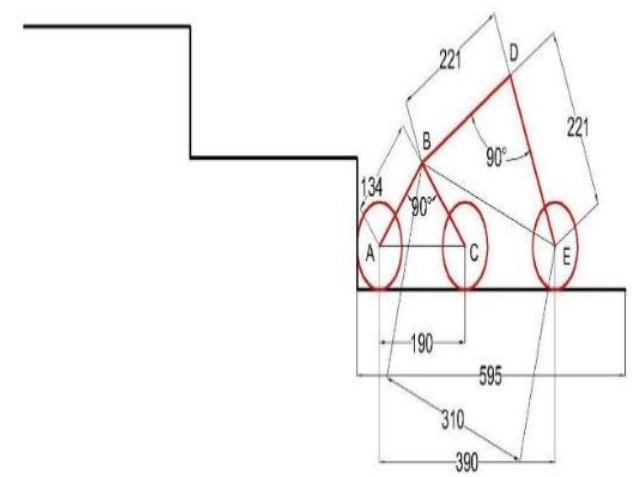

Fig. 1. Cad drawing for first triangle

Now, need to obtain the distance between first and second wheel through CAD software $(190 \mathrm{~mm})$. Considering the right angled triangle $\mathrm{ABC}$,

Using Pythagoras in $\triangle \mathrm{ABC}$ (Fig. 2.) assume lengths $\mathrm{AB}$ and $\mathrm{BC}$ is $\mathrm{X}$.

$\mathrm{AC}^{2}=\mathrm{AB}^{2}+\mathrm{BC}^{2}$

$190^{2}=\mathrm{x}^{2}+\mathrm{x}^{2}$

$190^{2}=2 x^{2}$

$\mathrm{x}=134 \mathrm{~mm}$

Hence, $\mathrm{AB}=\mathrm{BC}=134 \mathrm{~mm}$ (Fig. 2.)

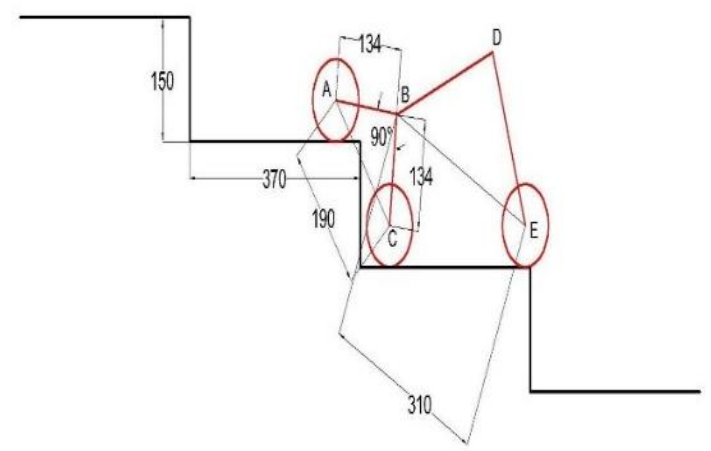

Fig. 2. Cad drawing for second triangle

Similarly, to find dimensions for rocker linkages first two wheel pairs should be placed at horizontal position. Third wheel pair should nearly complete its rising before starting of rising of first pair of wheel. By placing wheel in such manner we obtained dimension of link BC $(311 \mathrm{~mm})$.

Now consider $\triangle B D E$ (Fig. 3.),

$\mathrm{BE}^{2}=\mathrm{BD}^{2}+\mathrm{DE}^{2}$

$311^{2}=2 \mathrm{y}^{2}$

$\mathrm{y}=221 \mathrm{~mm}$

Hence, $\mathrm{BD}=\mathrm{DE}=221 \mathrm{~mm}$ (Fig. 3.)

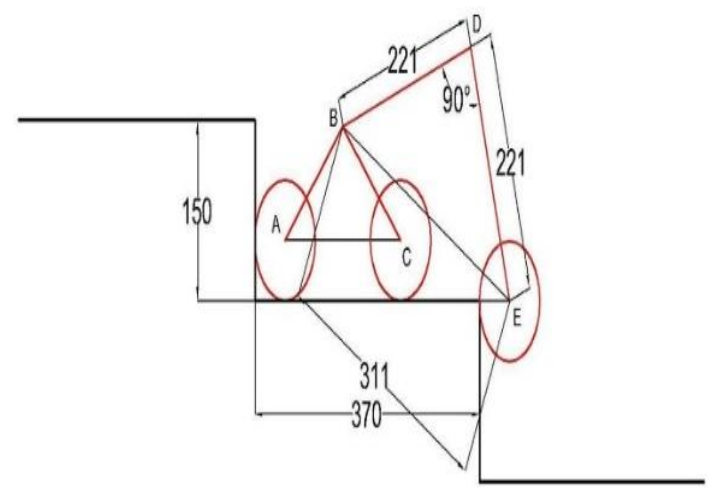

Fig. 3. CAD drawing of both triangles

By considering all these lengths and angles we have drawn whole mechanism. Above Fig. 3, shows all dimensions of robot. We take acrylic width is $40 \mathrm{~mm}$ suitable for drilling $15 \mathrm{~mm}$ diameter holes.

\section{B. Drawing}

After the calculation of triangle dimension using CAD software 2D drawing is prepared as per calculated dimension and same drawing views are shown in Fig. 4.

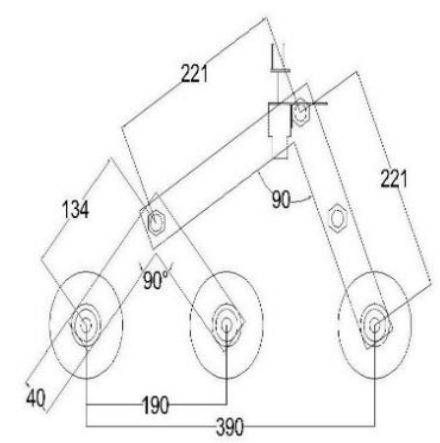

FRONT VIEW

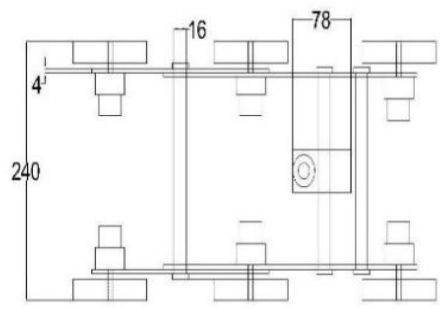

\section{TOP VIEW}

Fig. 4. 2D Drawing of Rocker Bogie Mechanism

\section{Design \& Selection of Wheel}

Design of wheel is required at velocity up to $0.5 \mathrm{~m} / \mathrm{s}$. Assume speed is $60-100 \mathrm{rpm}$ motor. Using velocity relation velocity is calculated for assumed speed. Using calculated velocity value need to find out diameter of wheel is $95.35 \mathrm{~mm}$. Hence we select the wheel of $100 \mathrm{~mm}$ diameter (standard wheel).

Selection of rubber thread bonded to the wheel makes it light weight and durable, provides excellent traction, 


\section{IAR JSET}

Vol. 4, Special Issue 1, January 2017

friction. These plastic wheels (as shown in Fig. 5.) offer a low cost solution that is durable enough for a combat robot yet still light enough to be practical. For robot used six wheels.

Wheel Diameter: $100 \mathrm{~mm}$

Wheel Width : $20 \mathrm{~mm}$

Shaft Diameter : $6 \mathrm{~mm}$

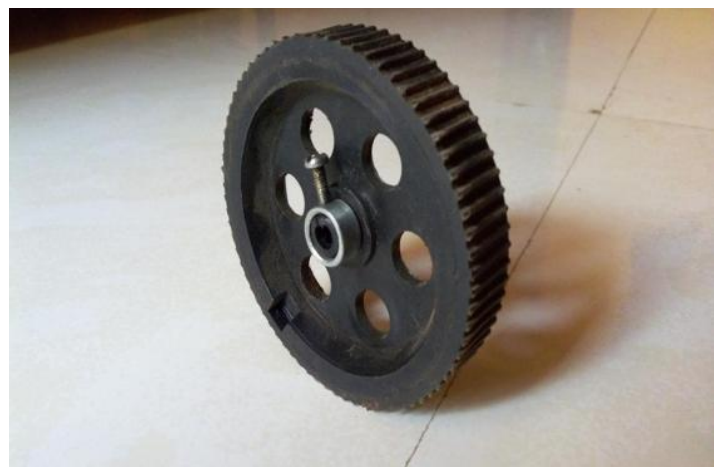

Fig. 5. Photo Image of Rubber Wheel

D. Selection of acceleration for robot

For a typical robot on flat terrain, it's needed to take acceleration about half of maximum velocity. Maximum velocity of robot is $0.5 \mathrm{~m} / \mathrm{s}$. Hence the acceleration of robot will be $0.5 / 2$ means $0.25 \mathrm{~m} / \mathrm{s}^{2}$. This means it would take 2 seconds to reach maximum speed. If robot is going up inclines (as per Equ. No.1) or through rough terrain, you will need a higher acceleration due to countering gravity. We needed to climb the angle upto $45^{\circ}$. Hence,

\section{Acceleration of inclines}

$$
\begin{gathered}
=\frac{9.81 * \sin (\text { angle of inclination }) * \pi}{180} \\
=0.121 \mathrm{~m} / \mathrm{s}^{2}
\end{gathered}
$$

Total Acceleration $=0.25+0.121=0.371 \mathrm{~m} / \mathrm{s}^{2}$

\section{IV.PERFORMANCE AT DIFFERENT CONDITIONS}

As per the ground level experimentation by rocker bogie manufactured; tested found that the performance satisfactory below are the result are shown see fig. 6- 10 on different obstacle and different surfaces.

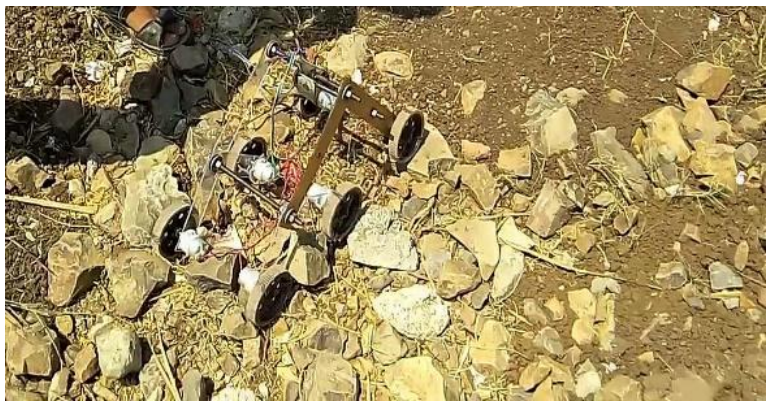

Fig. 6. Photo image of on rough surface

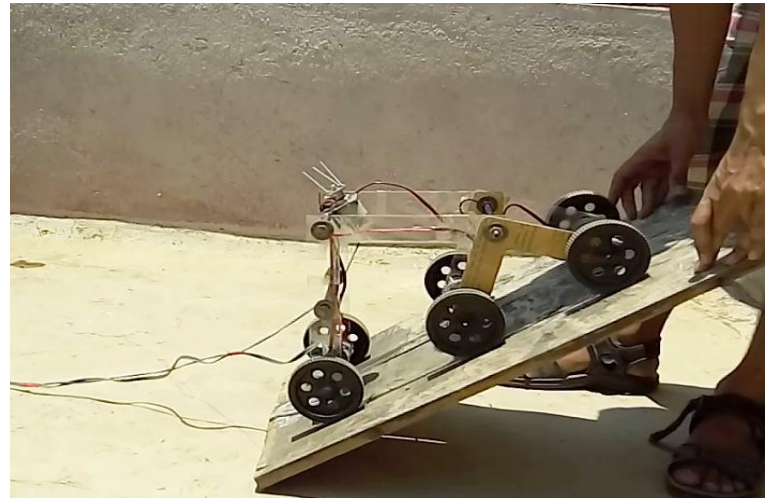

Fig. 7. Photo image of on angle surface about $45^{\circ}$ inclination

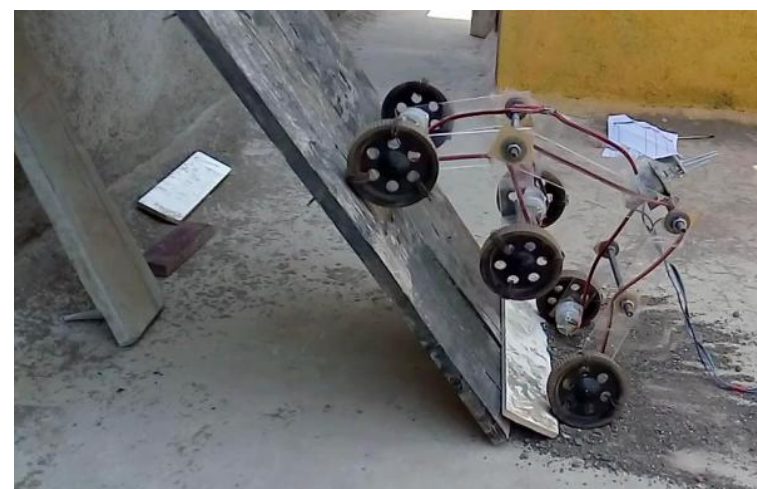

Fig. 8. Photo image of on angle surface about $75^{\circ}$ inclination

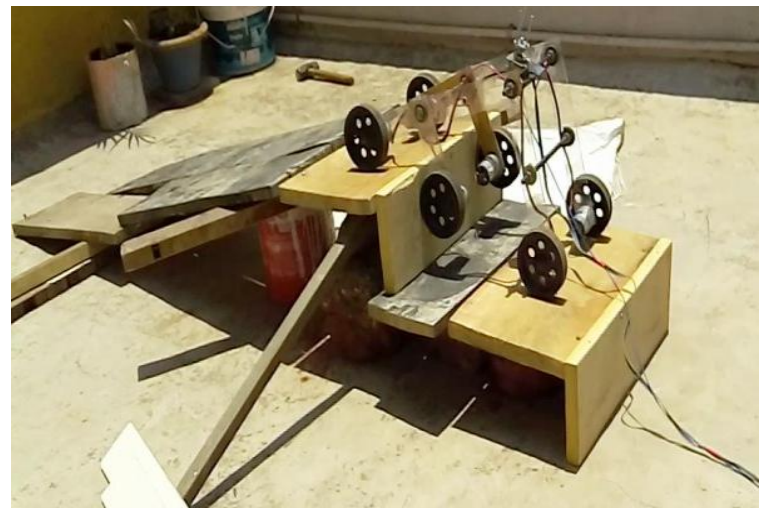

Fig. 9. Photo image stair Climbing

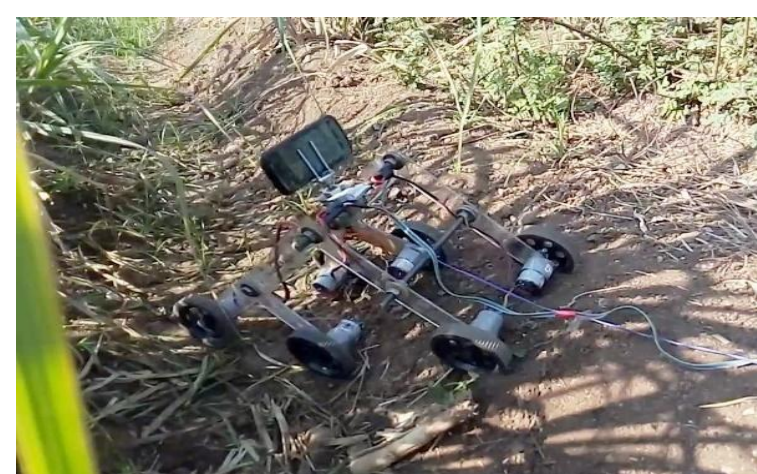

Fig. 10. Photo image in Farm with AV recording through IP web cam 
IARJSET

\section{CONCLUSION}

This work shows how rocker bogie system works on different surfaces. As per the different weight acting on link determines torque applied on it. By assuming accurate stair dimensions, accurately dimensioned rocker bogie can climb the stair with great stability. The design and manufactured model can climb the angle up to $45^{\circ}$. Also we tested for the Web cam with AV recording mounted on rocker bogie system and found satisfactorily performance obtains during this test camera has rotated around $360^{\circ}$. During stair climbing test for length less than $375 \mathrm{~mm}(15$ inch) system cannot climb the stair. It can be possible to develop new models of rocker bogie which can climb the stairs having low lengths.

\section{REFERENCES}

[1] P. Panigrahi, A. Barik, Rajneesh R. \& R. K. Sahu, "Introduction of Mechanical Gear Type Steering Mechanism to Rocker Bogie", Imperial Journal of Interdisciplinary Research (IJIR) Vol-2, Issue-5, ISSN: 2454-1362,2016.

[2] A. Bhole, S. H. Turlapati, Raja shekhar V. S, J. Dixit, S. V. Shah, Madhava Krishna K, "Design of a Robust Stair Climbing Compliant Modular Robot to Tackle Overhang on Stairs" arXiv:1607.03077v1 [cs.RO], 11 Jul 2016.

[3] M. D. Manik, A. S. Chauhan, S. Chakraborty, V. R. Tiwari, "Experimental Analysis of climbing stairs with the rocker-bogie mechanism", Vol-2 Issue-2 P.No. 957-960IJARIIE-ISSN(O)-23954396, 2016.

[4] B. D. Harrington and C. Voorhees, "The Challenges of Designing the Rocker-Bogie Suspension for the Mars Exploration Rover", Proceedings of the 37th Aerospace Mechanisms Symposium, Johnson Space Center, page No. 185-1985, May 19-21, 2004.

[5] Y. L. Maske, S. V. Patil, S. Deshmukh, "Modeling and MBD simulation of stairclimbing robot with rocker bogie Mechanism", International Journal of Innovative Research in Technology, 101743, Volume 1 Issue 12, Page no. 267-273,ISSN: 2349-6002, 2015

[6] N. Yadav, B. Bhardwaj, S. Bhardwaj, "Design analysis of Rocker Bogie Suspension System and Access the possibility to implement in Front Loading Vehicles", IOSR Journal of Mechanical and Civil Engineering, e-ISSN: 2278-1684,p-ISSN: 2320-334X, Volume 12, Issue 3 Ver. III, PP 64-67, May - Jun. 2015.

[7] L. Bruzzone and G. Quaglia, "Review article: locomotion systems for ground mobile robots in unstructured environments", Mech. Sci., 3, 49-62, 2012. DOI:10.5194/ms-3-49-2012

[8] F. Ullrich, A. Haydar G., S. Sukkarieh, "Design Optimization of a Mars Rover's Rocker-Bogie Mechanism using Genetic Algorithms", Proceedings from 10th Australian Space Science Conference, Page No. 199-210, 2010.

\section{BIOGRAPHIES}

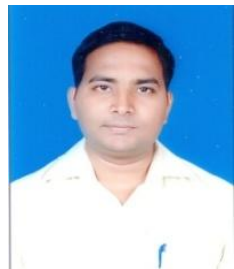

Dhananjay S. Chinchkar received his Bachelors Degree in Automobile Engineering from the Rajarambapu institute of technology, Islampur in 2009; Masters in Automobile Engineering from the Rajarambapu institute of technology, Islampur in 2013. Currently is working as an assistant professor at AGTI'S DACOE, Karad since 2012. His research interest in the areas are IC Engine, automobile, fuel additives, and lubricants.

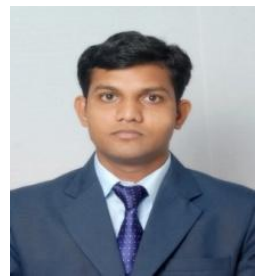

Sameer S. Gajghate received his Bachelors Degree in Mechanical Engineering from the Umrer college of Engg. Umrer in 2009; Masters in Mechanical- Heat Power Engg. from the Government College of Engineering, Karad in 2011. Currently is working as an assistant professor at AGTI'S DACOE, Karad since 2012. His research interests in the areas are heat transfer enhancement, CFD, Microchannel cooling techniques. 